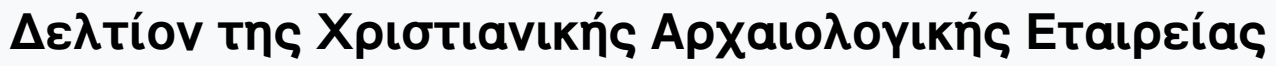

Tóp. 1 (1892)

$\Delta \varepsilon \lambda$ Tíov XAE 1 (1884-1891), Пврíoঠoç A'

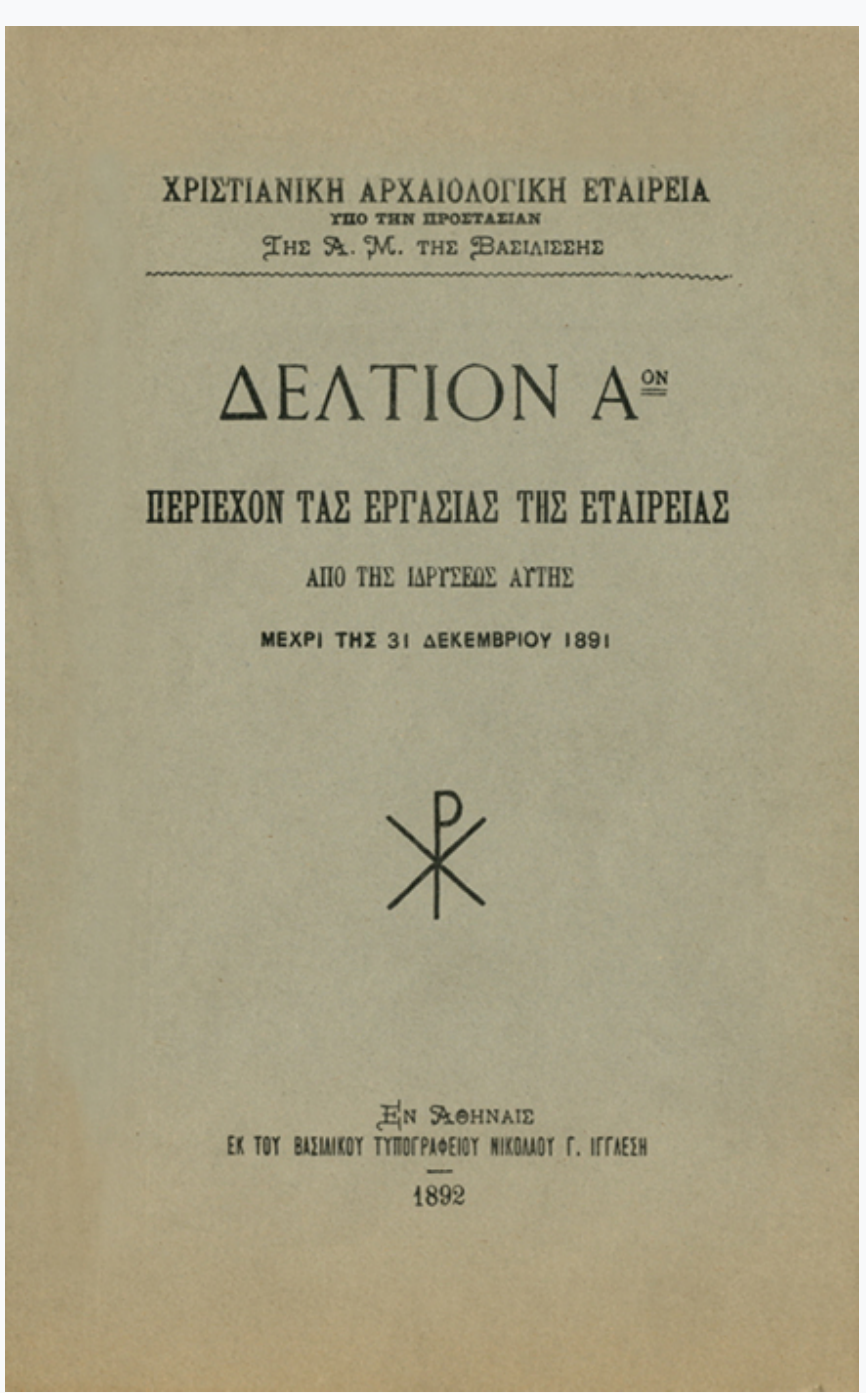

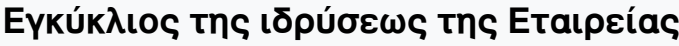

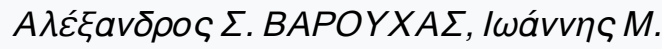
$\triangle A M B E P \Gamma H \Sigma$

doi: $\underline{10.12681 / \text { dchae. } 1485}$

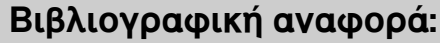

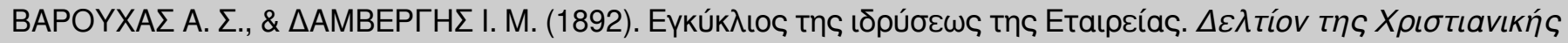

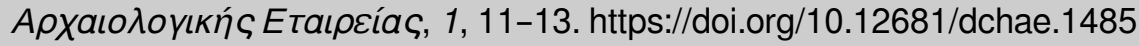




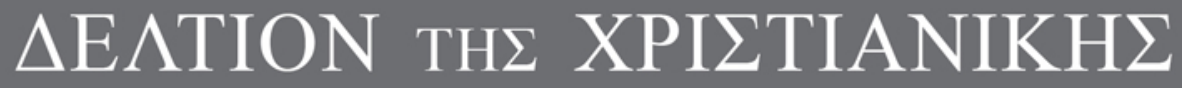 APXAIO $\Lambda$ OГIKH $\Sigma$ ETAIPEIA $\Sigma$}

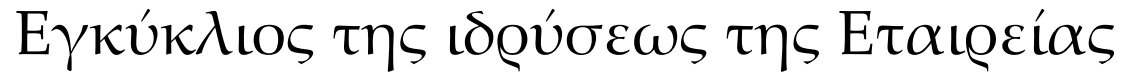

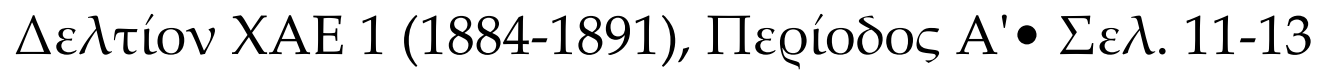

A@HNA 1892 


\section{ETKRKAIOL THE ISPRELQL THE ETAIPELAL}

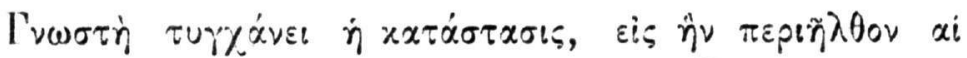

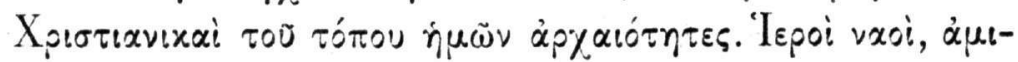

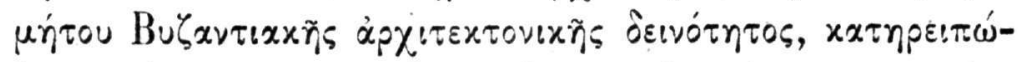

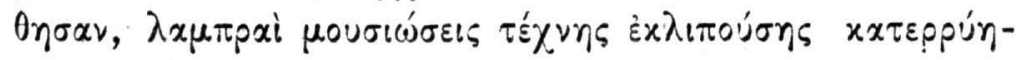
$\sigma \alpha \nu$ xai $\alpha \pi \dot{c} \lambda \lambda u v \tau \alpha l, \chi_{p}$

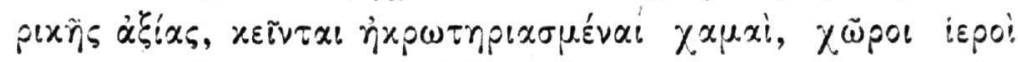

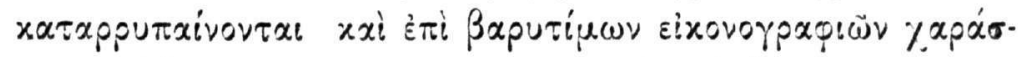

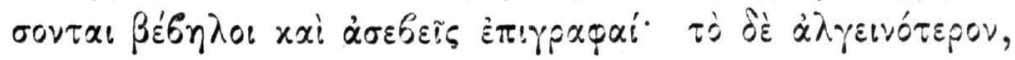

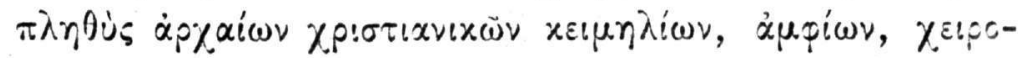

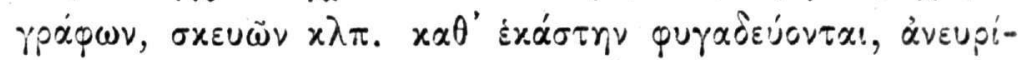

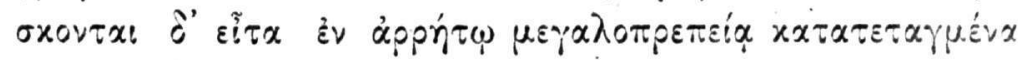

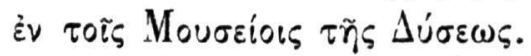

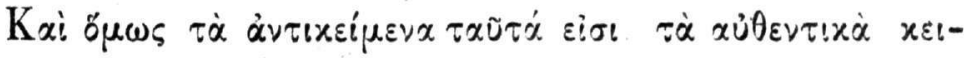

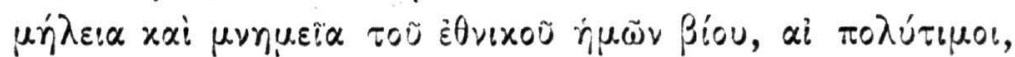

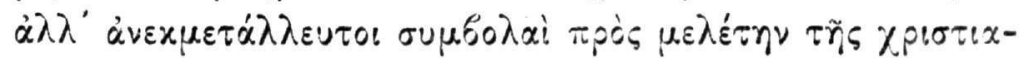

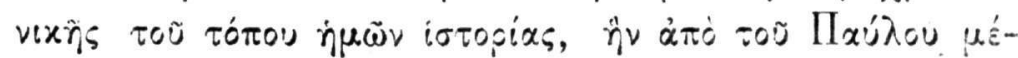

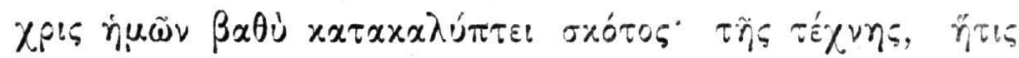

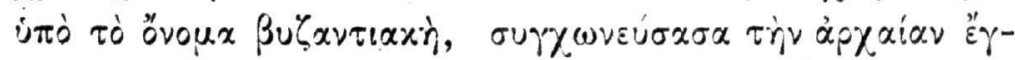

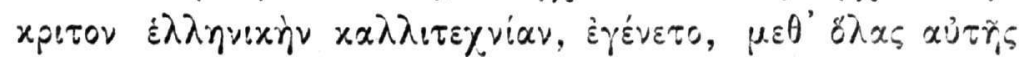

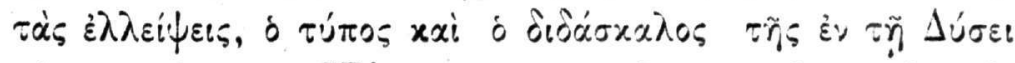

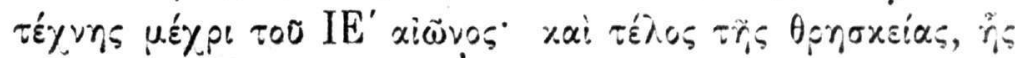

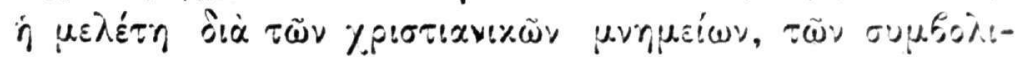

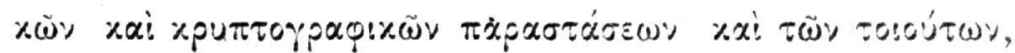

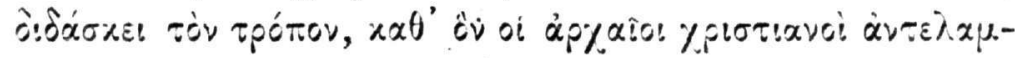

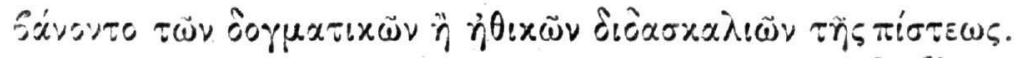

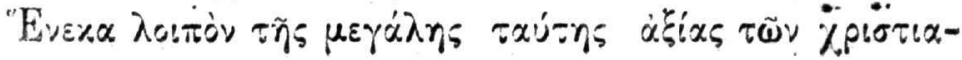




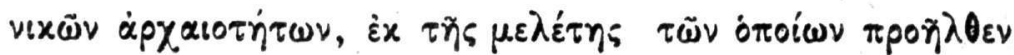

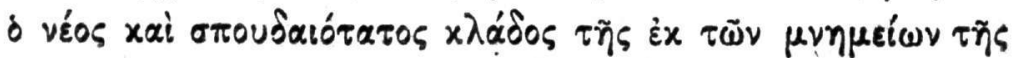

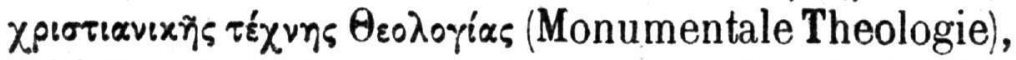

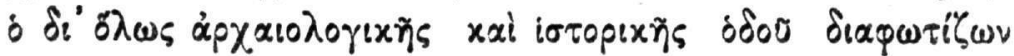

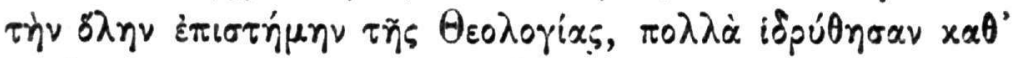

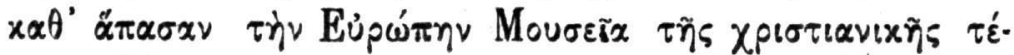

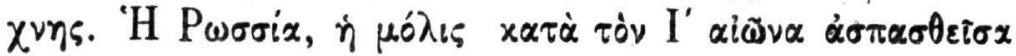

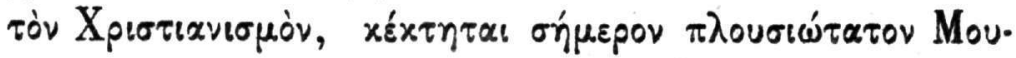

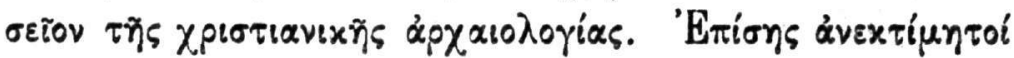

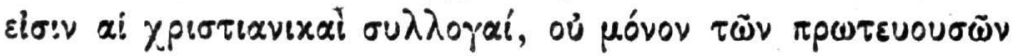

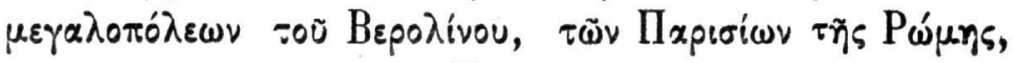

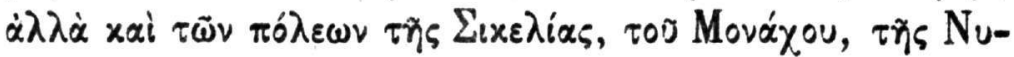

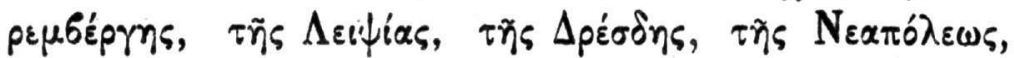

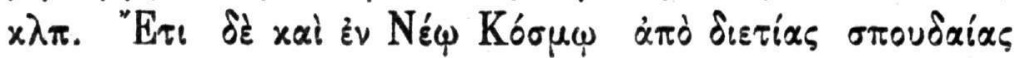

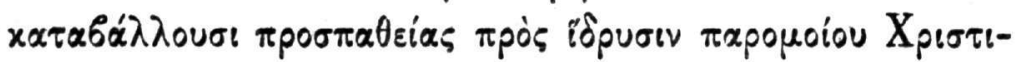

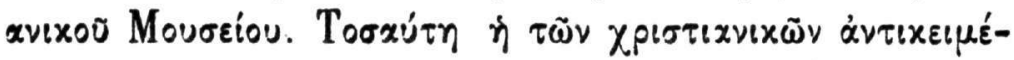

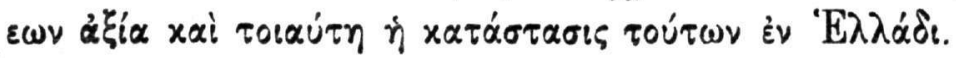

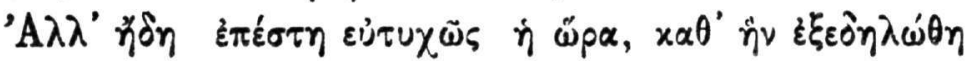

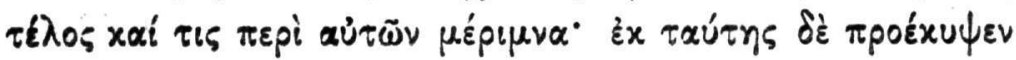

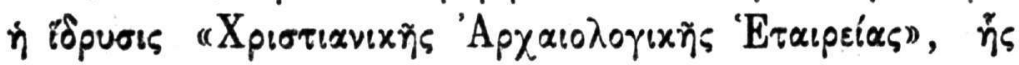

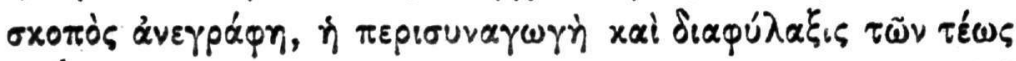

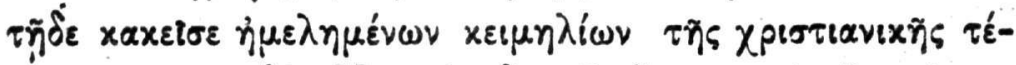

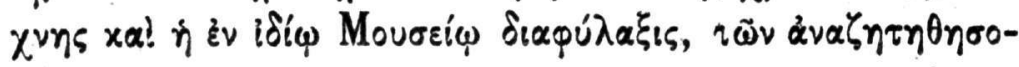

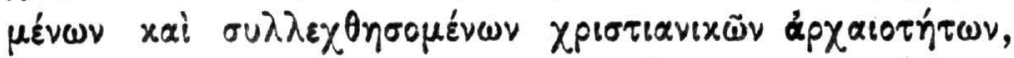

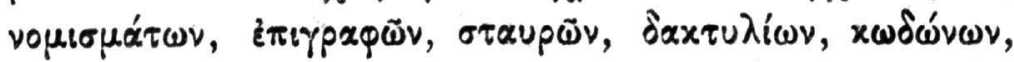

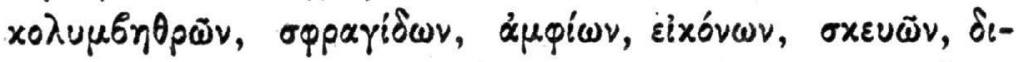

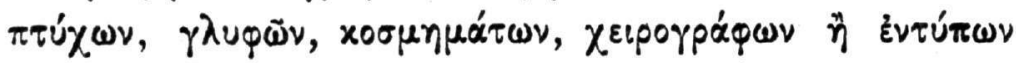

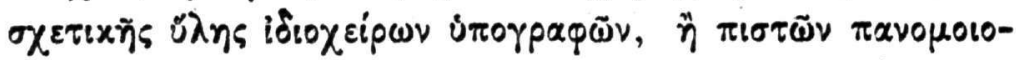

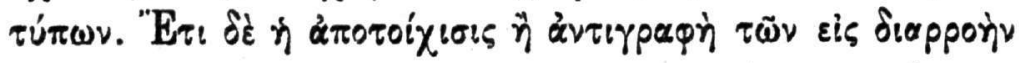

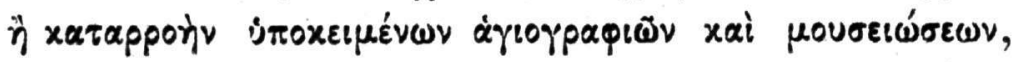

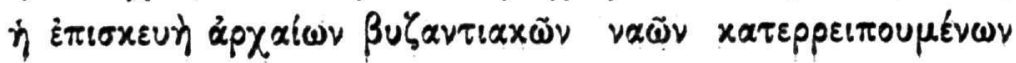




\section{$-13-$}

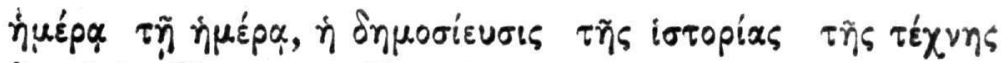

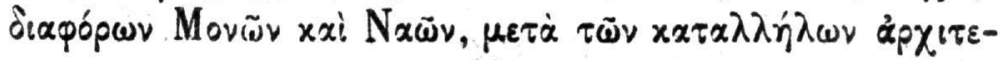

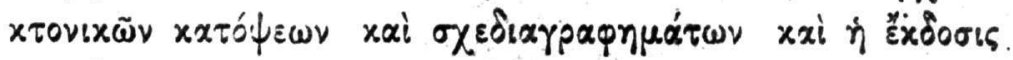

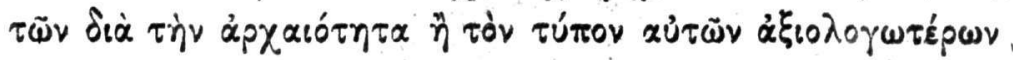

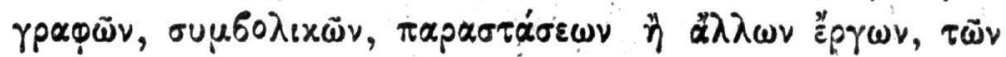

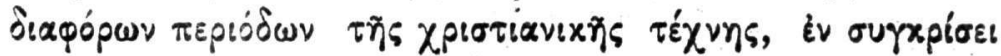

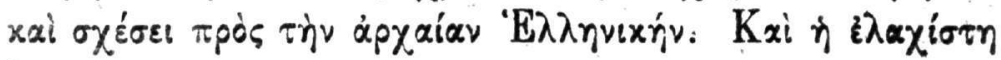

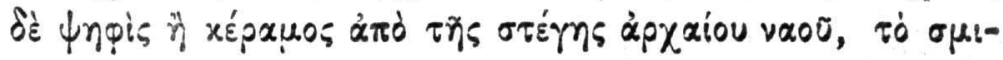

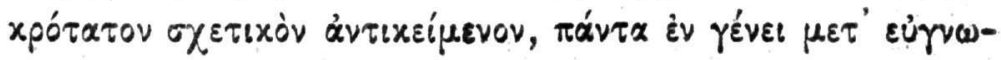

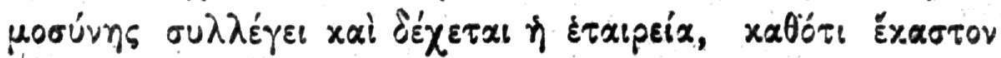

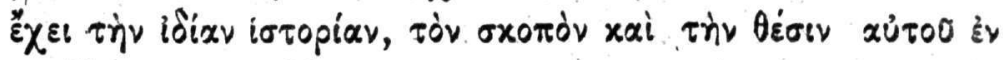

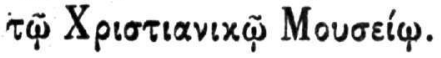

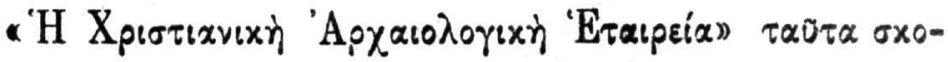

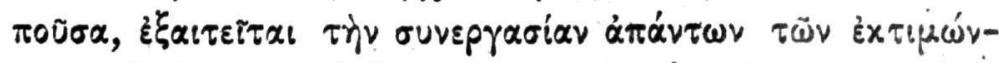

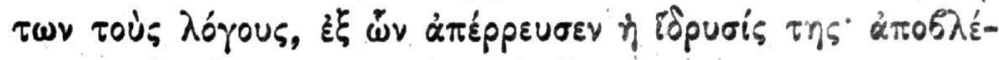

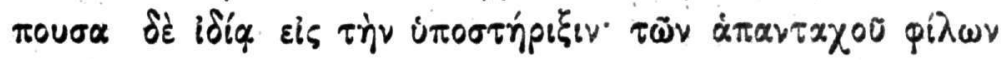

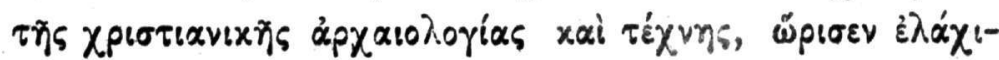

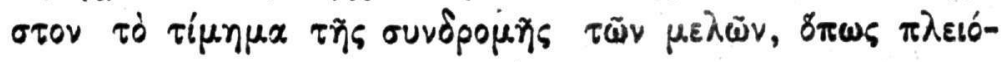

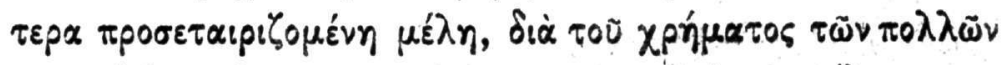

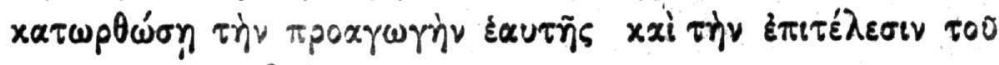

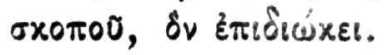

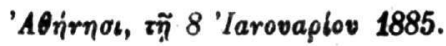

'O mporionos

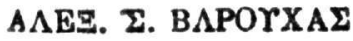

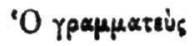

I. M. $\triangle \mathrm{AMBEPTH \Sigma}$ 